\title{
Recurring spontaneous pneumothorax concomitant with menstruation
}

\author{
R OSEMAR Y DAVIES \\ From the Chest Clinic, Warneford Hospital, Leamington Spa
}

\begin{abstract}
Details are given of nine cases of recurrent spontaneous pneumothorax concomitant with menstruation: of these, four are culled from the literature. In every case the time interval between the onset of menstruation and the development of a pneumothorax has been very close, and from the evidence presented some causal relationship is envisaged. Endometriosis is considered as a possible cause. Two of the patients had proven endometriosis of the diaphragm and this condition was almost certainly present in a third patient. Three patients had pelvic endometriosis. The pneumothorax always occurred on the right side, and the possible significance of this is discussed.
\end{abstract}

Recurrent spontaneous pneumothorax in association with menstruation was first noted by Maurer, Schaal, and Mendez in 1958. These authors described a 35-year-old woman who had 15 proven episodes of right spontaneous pneumothorax between November 1952 and March 1954. Every episode had come on during the period of menstruation. At thoracotomy the lung parenchyma looked normal and there was no obvious air leak ; in the central portion of the right leaf of the diaphragm was a circumscribed oval area of attenuation measuring $4 \times 3 \mathrm{~cm}$.: on its surface were numerous purplish-red nodules and there was a small central perforation. The diseased area was excised and the defect in the diaphragm sutured. The disease had involved the whole thickness of the diaphragm. Another small solitary nodule was also noted on the superior surface of the diaphragm; this also was excised. Histological examination showed endometriosis of the right leaf of the diaphragm, resulting in perforation and the deposition of endometrial implants on the intrathoracic surface of the diaphragm. This patient was subsequently found to have pelvic endometriosis.

In 1961 Wingfield described a woman of 33 who had experienced $40-45$ bouts of severe chest pain and dyspnoea, the symptoms always occurring at the onset of menstruation. On two such occasions when she was radiographed she was found to have a right-sided pneumothorax. At thoracotomy no abnormality was found.

Mayo (1963) reported a woman who was estimated to have had 23 episodes of right spontaneous pneumothorax. He stated that there had been radiological confirmation of the pneumothorax, but it is not explicitly stated that this was obtained on each occasion. He mentioned that air was never observed beneath the diaphragm. Each episode $\stackrel{\mathbb{Q}}{\varrho}$ occurred within a day or two of the beginning of $\overrightarrow{\vec{D}}$ a menstrual period. At thoracotomy emphysema- 3 tous changes were noted in all lobes of the right lung, and air leaks were present at the apex of the upper lobe.

Kovarik and Toll (1966) reported a further case $\underset{x}{\stackrel{0}{\Perp}}$ of endometriosis of the right diaphragm in a patient who presented with recurrent spontaneous. pneumothorax at the time of menstruation. Theiro patient was a 38-year-old woman who had had six such episodes. Eight months prior to their first은 seeing her this patient had started taking norethyn- $\rightarrow$ odrel with mestranol (Enavid), and for the nexto five months she had no pneumothorax; she then stopped the hormones and three days later developed a spontaneous pneumothorax on the first $\tilde{O}$ day of menstruation. She restarted the Enavid, but ${ }_{\omega}^{N}$ three months later she had another pneumothorax 0 the day after 'break-through' vaginal bleeding hade begun. At operation a lesion having the appear- $-\frac{\mathbb{\Phi}}{}$ ance of an endometrial implant was seen on the? intrathoracic surface of the right diaphragm. This was removed and histology confirmed the diag-용 nosis of diaphragmatic endometriosis.

The purpose of this paper is to describe five further cases of recurring spontaneous pneumothorax concomitant with menstruation. 


\section{CASE REPORTS}

CASE 1 Mrs. M. T., aged 39, who had two children, developed a right spontaneous pneumothorax in May 1963. This episode was not associated with menstruation, but she had further right-sided pneumothoraces between January 1964 and May 1965 which always occurred within 48 hours of the onset of menstruation. These episodes are summarized as follows:

$\begin{array}{ccc}\text { Pneumothorax } & \begin{array}{c}\text { Date of } \\ \text { Commencement } \\ \text { of Period }\end{array} & \begin{array}{c}\text { Radiographic } \\ \text { Confirmation }\end{array} \\ 27.5 .63 & 5.6 .63 & + \\ 26.1 .64 & 28.1 .64 & + \\ 19.4 .64 & 18.4 .64 & + \\ 5.7 .64 & 4.7 .64 & + \\ 31.7 .64 & 1.8 .64 & - \\ 29.9 .64 & 26.9 .64 & - \\ 17.11 .64 & 18.11 .64 & - \\ 15.12 .64 & 14.12 .64 & - \\ 10.1 .65 & 10.1 .65 & - \\ 30.3 .65 & 31.3 .65 & - \\ 25.4 .65 & 27.4 .65 & + \\ 21.5 .65 & 22.5 .65 & +\end{array}$

On each occasion when radiological confirmation of the pneumothorax was obtained follow-up films showed complete re-expansion and there was no abnormality of the lung fields.

By May 1965 the association was so striking that the possibility of a hormonal explanation was considered and ovulation was suppressed by giving norethisterone, $5 \mathrm{mg}$. daily, from the 5 th to the 25 th days of each menstrual cycle. For the next five months there were no episodes of pneumothorax, but a further right-sided pneumothorax occurred on 4 November 1965 and yet another on 1 January 1966. On both these occasions there was no relationship between the pneumothorax and the commencement of 'withdrawal' vaginal bleeding. Norethisterone was discontinued on 13 March 1966. Further right spontaneous pneumothoraces occurred on 22 March and 4 May. At thoracotomy on 31 May 1966 no abnormality was seen and talc pleurodesis was carried out. The patient has remained well since.

CASE 2 Mrs. E. G., aged 40, who had two children, had an ovarian cyst removed in 1953. This was considered to be endometriomatous as it contained much altered hlood. In February 1965 she had her first episode of right-sided spontaneous pneumothorax. Her lung re-expanded quickly. She had further rightsided pneumothoraces in July 1965 and in January, April, and July 1966. On every occasion the pneumothoraces occurred on the first day of menstruation. After her fifth pneumothorax a right thoracotomy was performed. The lung appeared normal; there were no bullae and there was no evidence of air leak. Several disc-like black lesions were seen on the diaphragm, the largest being approximately $1 \mathrm{~cm}$. in diameter. A biopsy was taken of the largest of these lesions, which released a small quantity of dark fluid. Unfortunately no histology is available.

CASE 3 Mrs. B. K. had a wedge resection of the ovaries in 1961 when she was aged 30. The surgeon reported extensive pelvic endometriosis. From the summer of 1961 onwards she had attacks of severe right-sided chest pain of varying intensity but always related to her periods. The pain started three days before the onset of a period and continued until the first or second day of menstruation. She described the pain as sharp and shooting to the tip of her shoulder. When the pain was present she was often short of breath. She had a chest radiograph on three occasions in December 1964, October 1965, and March 1966 and was each time found to have a right-sided pneumothorax: on every occasion there was satisfactory re-expansion of the lung. A right thoracotomy performed on 14 June 1966 was reported on as follows: 'Parietal pleura thin and lung fully expanded. Right pleurectomy performed, lung biopsy taken. Histology: Sections of the lung tissue show some emphysema, but there is no evidence of any inflammatory process. A mild quiescent chronic pleurisy is present also'. In January 1967 she again had some chest pain at the time of menstruation, but had no chest radiograph at this time. When seen on 9 February 1967 she was menstruating but had no chest pain and a chest film was normal.

Case 4 Mrs. S. S., aged 34, had two children. During the winter of 1963-4 the patient had occasional sharp pain in the right pectoral region lasting three or four days at a time. There was no associated dyspnoea and she did not have a chest radiograph. (In retrospect she thinks that she had this pain once a month but does not remember specific details.) In September, October, and November 1965 she experienced right-sided chest pain at the time of menstruation, and on the third occasion (12 November 1965) she had a chest radiograph which showed a right spontaneous pneumothorax. The lung re-expanded satisfactorily and she had no chest symptoms at the time of menstruation in December 1965 and in January 1966. Subsequent events are summarized as follows:

$\begin{array}{ccc}\begin{array}{c}\text { Date of Onset } \\ \text { of Period }\end{array} & \begin{array}{c}\text { Chest } \\ \text { Pain or } \\ \text { Discomfort }\end{array} & \begin{array}{c}\text { Radiograph } \\ 26.2 .66\end{array} \\ 24.3 .66 & + & 0 \\ 4.66 & 0 & 0 \\ 5.66 & + & 0 \\ 14.6 .66 & + & 0 \\ 9.7 .66 & 0 & + \\ 5.8 .66 & + & 0 \\ 28.8 .66 & + & 0 \\ 23.9 .66 & 0 & 0 \\ & + & +\end{array}$




$\begin{array}{ccc}\begin{array}{c}\text { Chest } \\ \text { Date of Onset } \\ \text { of Period }\end{array} & \begin{array}{c}\text { Pain or } \\ \text { Discomfort }\end{array} & \begin{array}{c}\text { Radiograph } \\ 19.10 .66\end{array} \\ 11.66 & + & 0 \\ 14.12 .66 & + & 0 \\ 9.1 .67 & 0 & 0 \\ 2.2 .67 & + & 0 \\ 27.2 .67 & + & 0 \\ 27.3 .67 & + & - \\ 21.4 .67 & +(28.3 .67) & +(28.3 .67) \\ 16.5 .67 & + & + \\ & + & + \\ \text { No chest radiograph } & & + \\ \text { Normal chest radiograph } & \\ \text { Spontaneous pneumothorax } & \end{array}$

On each occasion when a radiograph demonstrated a pneumothorax follow-up films showed full reexpansion.

In June 1967 she started taking Enavid and for the next three months she had no chest pain associated with menstruation and chest films taken on the first or second day of each period were normal.

CASE 5 Mrs. E. G. was born in 1918. Her symptoms started when she was aged 32. She developed pain in the back and right side of the chest just before the onset of her periods; there was some associated dyspnoea. These symptoms persisted for three years and it was not until 9 May 1953 that she had a chest radiograph at the actual time of her chest pain (in the past she had had several normal chest films but each time these had been taken between the episodes of pain). The film on 9 May showed a right spontaneous pneumothorax and she had further episodes of right spontaneous pneumothorax with three of her next four periods. In September 1953 a thoracotomy was performed; no abnormality was seen and the pleural cavity was fused with olive oil. Subsequently she had no further pneumothoraces.

This patient estimated that she had had 30 episodes in all. The association of symptoms seemed so bizarre that they were for a long time considered to be psychogenic in origin. Her normal chest radiographs lent support to this view and it was not until a film was taken on the actual day of the pain that the true nature of the condition was revealed.

\section{DISCUSSION}

The five cases here described and the four already reported in the literature show a number of features in common. The relationship between the development of the pneumothorax and the onset of menstruation is, in every case, a very close one, the respiratory symptoms occurring either in the 24 hours before the onset of menstruation or during the first two days of the period. Each patient has had recurrent episodes of right-sided pneumothorax, and the total number of proven attacks is such that coincidence can be ruled out and one must accept some causal relationship.

The ages of the patients described range from 29 to 40 years. This in itself suggests a different aetiology from the so-called idiopathic spontaneous pneumothoraces since, in my experience, these latter show a peak incidence at a younger age. The decade $30-40$ years, however, is the age $\vec{x}$ at which pelvic endometriosis is most commonly seen. Two of the nine cases here recorded are known to have had pelvic endometriosis and a $\dot{\omega}$ third patient had had an ovarian cyst removed. A $O$ thoracotomy or a thoracoscopy was performed in 윽 eight cases, and endometriosis of the diaphragm was found in certainly two and probably three $c$ patients. In five of the patients there was no evidence of thoracic endometriosis, but one of these $\vec{\bullet}$ is known to have had pelvic endometriosis in the $\varnothing_{\infty}$ past. It does, therefore, appear that endometriosis may be a causal factor in the condition, though endometriosis of the diaphragm would not, of itself, cause pneumothoraces. One of the surgeons who saw the deposits on the diaphragm noted that $\frac{\mathrm{O}}{\mathbb{D}}$ the deposits were small and might easily be over- $Q$ looked: it is conceivable that similar small, but $\overrightarrow{0}$ unnoticed, lesions were present on the lung sur- 3 face, and the rupture of one of these might result in an air leak. The association of haemothorax with pleural endometriosis is well recognized. In none of the cases here described, however, was there a haemothorax, and indeed there was not $x$ even the small amount of pleural fluid sometimes $\frac{3}{3}$ seen in cases of idiopathic spontaneous pneumothorax. This absence of any bleeding is surprising if endometriosis is in fact the aetiological factor.

For many years progesterone has been used in the treatment of pelvic endometriosis, with but little success until relatively recently, when various progesterone substitutes have been successfully N used. Norethynodrel is the substance most $N$ commonly used, often in combination with N 3-methyl ether ethinoestradiol. This combination ${ }^{\omega}$ should be given in a dosage sufficient to suppress both ovulation and menstruation.

Hormone therapy is mentioned in only three of these cases of pneumothorax associated with menstruation. In Kovarik and Toll's case (1966) itō seemed that Enavid temporarily influenced the $\mathbb{\Omega}_{\overparen{Q}}$

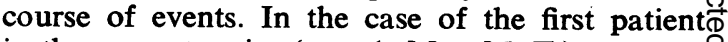
in the present series (case 1, Mrs. M. T.) pneumo- $\frac{}{0}$ thoraces had become very frequent before the institution of hormone therapy (she had probablyo had 10 episodes in the preceding 12 months) 
T A B L E

\begin{tabular}{|c|c|c|c|c|c|c|c|c|}
\hline Source & & $\begin{array}{c}\text { Age at } \\
\text { 1st Proven } \\
\text { Spontaneous } \\
\text { Pneumothorax }\end{array}$ & $\underset{\text { State }}{\text { Marital }}$ & Para & Side & $\begin{array}{l}\text { Thoracotomy } \\
\text { (T) or } \\
\text { Thoracoscopy } \\
\text { (Th) }\end{array}$ & $\begin{array}{c}\text { Pleural } \\
\text { Endometriosis }\end{array}$ & $\begin{array}{c}\text { Pelvic } \\
\text { Endometriosis }\end{array}$ \\
\hline 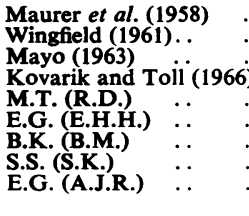 & \begin{tabular}{l|l}
$\cdots$ & \\
$\cdots$ & \\
6 & \\
$\cdots$ & \\
$\cdots$ & \\
$\cdots$ & \\
$\cdots$ &
\end{tabular} & $\begin{array}{l}35 \\
33 \\
29 \\
34 \\
36 \\
40 \\
34 \\
32 \\
35\end{array}$ & $\begin{array}{l}\mathbf{M} \\
\mathbf{M} \\
\mathbf{M} \\
\mathbf{M} \\
\mathbf{M} \\
\mathbf{M}\end{array}$ & $\begin{array}{l}3 \\
2 \\
2 \\
2 \\
2\end{array}$ & $\begin{array}{l}\mathbf{R} \\
\mathbf{R} \\
\mathbf{R} \\
\mathbf{R} \\
\mathbf{R} \\
\mathbf{R} \\
\mathbf{R} \\
\mathbf{R} \\
\mathbf{R}\end{array}$ & $\begin{array}{l}\mathbf{T} \\
\mathbf{T} \\
\mathbf{T} \\
\mathbf{T} \\
\mathbf{T h} \\
\mathbf{T} \\
\mathbf{T} \\
\overline{T h}\end{array}$ & $\begin{array}{l}+ \\
\overline{-} \\
+ \\
\overline{+} \\
\overline{-} \\
-\end{array}$ & $\begin{array}{l}+ \\
- \\
- \\
- \\
+ \\
+ \\
-\end{array}$ \\
\hline
\end{tabular}

after starting hormone therapy she did not have a pneumothorax for five consecutive months, although subsequently she had further attacks while still on hormone therapy. It is as yet too soon to assess the influence of hormones on events in case 4.

In case 1 the hormone was given only in a dosage sufficient to prevent ovulation, and this may be why it was only partially successful. A more adequate dosage is being used for case 4 .

A striking feature in reviewing these cases is that the pneumothorax always occurred on the right side. Although only nine patients are reviewed the total number of pneumothoraces $(52$ proven episodes and numerous probable but unproven pneumothoraces) is sufficiently great to make this predilection for the right side appear significant when compared with other reported series of cases of spontaneous pneumothorax where the incidence does not have this pattern. In a personal series of 103 cases of 'idiopathic' spontaneous pneumothoraces, 57 of the pneumothoraces were on the right side and 46 on the left (men, R : L $43: 32$; women, R : L $14: 6$ ). Crowther (1955) reported a series in which the pneumothorax was right-sided in 37 cases and on the left in 22 . In reviewing the literature he found that $57 \%$ were on the right and $43 \%$ on the left and he pointed out that these proportions approximated to the volume relations of the right and left lungs. In a series of 13 cases of recurrent pneumothoraces in women (Slessor, 1967) the pneumothoraces were on the right in 5 , on the left in 6 , and bilateral in 2 . Thus it seems that some special factor must be sought to explain the rightsided nature of the pneumothoraces in this present series. An anatomical explanation may be that defects in the diaphragm are more common on the right than on the left, and thus any transdiaphragmatic spread of endometriosis would be more likely on this side.

On each occasion the pneumothorax has reexpanded rapidly and completely ; indeed many times the lung has been fully expanded in a few days. Thus it is important for a patient complaining of chest pain associated with menstruation to have a chest radiograph taken at the time of symptoms and not in the intervening weeks. Failure to take a film at the appropriate time led to the true nature of the condition being overlooked for several months in case 5 .

The findings in the various cases are summarized in the Table.

In conclusion, it appears that the syndrome of recurring spontaneous pneumothorax concomitant with menstruation is a definite clinical entity and endometriosis is envisaged as a possible cause.

My thanks are due to Dr. E. H. Hudson for his advice and encouragement and for allowing me to include one of his patients (case 2) in this series. I have also to thank Dr. John Robertson, Mr. Bryan Moore, and Dr. S. Kalinowski for allowing me to report patients under their care.

\section{REFERENCES}

Crowther, J. S. (1955). Spontaneous pneumothorax. A review of 61 cases. Tubercle (Edinb.), 36, 265.

Kovarik, J. L., and Toll, G. D. (1966). Thoracic endometriosis with recurrent spontaneous pneumothorax. J. Amer. med. Ass., 196, 595

Maurer, E. R., Schaal, J. A., and Mendez, F. L. (1958). Chronic recurring spontaneous pneumothorax due to endometriosis of the diaphragm. Ibid., 168, 2013.

Mayo, P. (1963). Recurrent spontaneous pneumothorax concomitant with menstruation. J. thorac. cardiovasc. Surg., 46. 415.

Slessor, B. V. (1967). Personal communication.

Wingfield, R. C. (1961). Chronic recurring spontaneous pneumothoraces associated with menstruation. Maryland med. J., 10 344.

\section{ADDENDUM}

Since this paper was submitted for publication a further series of three cases of spontaneous pneumothorax associated with menstruation has been reported (Crutcher, Wattuch, and Blue, 1967). The histories in these cases are in most respects similar to those already given and once more all the pneumothoraces occurred on the right side.

\section{REFERENCE}

Crutcher, R. R., Wattuch, T. L., and Blue, M. E. (1967). Recurring spontaneous pneumothorax associated with menstruation. spontaneous pneumothorax associar.
J. thorac. cardiovasc. Surg., $54,599$. 